\title{
FEATURES AND INITIAL RESULTS OF THE DIII-D ADVANCED TOKAMAK RADIATIVE DIVERTOR
}

\author{
by \\ R.C. O'NEILL, A.S. BOZEK, M.E. FRIEND, C.B. BAXI, E.E. REIS, \\ M.A. MAHDAVI, D.G. NILSON, ${ }^{\dagger}$ S.L. ALLEN, ${ }^{\dagger}$ and W.P. WEST
}

This is a preprint of a paper to be presented at the 18th IEEE/NPSS Symposium on Fusion Engineering, October 25-29, 1999, Albuquerque, New Mexico, and to be published in the Proceedings.

†Lawrence Livermore National Laboratory

\author{
Work supported by \\ the U.S. Department of Energy \\ under Contracts DE-AC03-99ER54463, and W-7405-ENG-48
}

GA PROJECT 30033

NOVEMBER 1999 


\section{DISCLAIMER}

This report was prepared as an account of work sponsored by an agency of the United States Government. Neither the United States Government nor any agency thereof, nor any of their employees, make any warranty, express or implied, or assumes any legal liability or responsibility for the accuracy, completeness, or usefulness of any information, apparatus, product, or process disclosed, or represents that its use would not infringe privately owned rights. Reference herein to any specific commercial product, process, or service by trade name, trademark, manufacturer, or otherwise does not necessarily constitute or imply its endorsement, recommendation, or favoring by the United States Government or any agency thereof. The views and opinions of authors expressed herein do not necessarily state or reflect those of the United States Government or any agency thereof. 


\section{DISCLAIMER}

Portions of this document may be illegible in electronic image products. Images are produced from the best available original document. 


\title{
Features and Initial Results of the DIII-D Advanced Tokamak Radiative Divertor
}

\author{
R.C. O’Neill, ${ }^{1}$ A.S. Bozek, ${ }^{1}$ M.E. Friend, ${ }^{1}$ C.B. Baxi, ${ }^{1}$ E.E. Reis, ${ }^{1}$ M.A. Mahdavi, ${ }^{1}$ D.G. Nilson, ${ }^{2}$ \\ S.L. Allen ${ }^{2}$ and W.P. West ${ }^{1}$ \\ $1_{\text {General Atomics, P.O. Box } 85608 \text {, San Diego, California } 92186-5608}$ \\ 2 Lawrence Livermore National Laboratory, Livermore, California
}

\begin{abstract}
The Radiative Divertor Program of DIII-D is in its final phase with the installation of the cryopump and baffle structure (Phase 1B Divertor) in the upper inner radius of the DIII-D vacuum vessel at the end of this calendar year. This divertor, in conjunction with the Advanced Divertor and the Phase 1A Divertor, located in the lower and upper outer radius of the DIII-D vacuum vessel respectively, provides pumping for density control of the plasma while minimizing the effects on the core confinement. Each divertor consists of a cryo/helium cooling ring and a shielded protective structure. The cryo/helium-cooled pumps of all three divertors exhaust helium from the plasma. The protective shielded structure or baffle structure, in the case of the divertors located at the top of the vacuum vessel, provides baffling of neutral charged particles and minimize the flow of impurities back into the core of the plasma. The baffles, which consist of water-cooled panels that allow for the attachment of tiles of various sizes and shapes, house gas puff systems. The intent of the puffing systems is to inject gas in and around the divertor to minimize the heat flux on specific areas on the divertor and its components. The reduction of the heat flux on the divertor minimizes the impurities that are generated from excess heat on divertor components, specifically tiles. Experiments involving the gas puff systems and the divertor structures have shown the heat flux can be spread over a large area of the divertor, reducing the peak heat flux in specific areas.
\end{abstract}

The three divertors also incorporate a variety of diagnostic tools such as halo current monitors, magnetic probes and thermocouples to monitor certain plasma characteristics as well as determine the effectiveness of the cryopumps and baffle configurations. The divertors were designed to optimize pumping performance and to withstand the electromagnetic loads from both halo currents and toroidal induced currents. Incorporated also into the designs of the structures is the capability to withstand the thermal gradient across the structures and the DIII-D vacuum vessel during operations and bakeout in which temperatures reach as high as $350^{\circ} \mathrm{C}$. The performance of the diagnostics and divertor systems with experimental results of the two existing systems are reported in this paper along with the baseline of the designs of the three divertor systems.

\section{INTRODUCTION}

The Radiative Divertor Program is well into the installation phase of the upper inner divertor (Phase 1B). This divertor, in conjunction with the upper outer divertor (Phase 1A) and the advanced divertor [1], located in the lower outer quadrant of the DIII-D vessel (Fig. 1), allows for the study of heat flux reduction in the immediate regions and particle and impurity control for high triangular plasma discharges.

The baffle structure common to all three of the divertors permits the distribution of the heat flux via radiation, thereby reducing the energetic particle impingement onto the divertor structures or, more specifically, the strikepoints. The baffle structures accomplish this by neutral gases that are puffed into the area and allow for the radiation/distribution of the heat of the plasma. The structures also limit the transport of the neutral gases and impurities into the core of the plasma based on their geometries and orientation to the plasma. The geometry of the structures can be modified to increase the divertor slot length and width. At present, the slot width for the two upper divertors is set at $23 \mathrm{~cm}$ (the distance from the

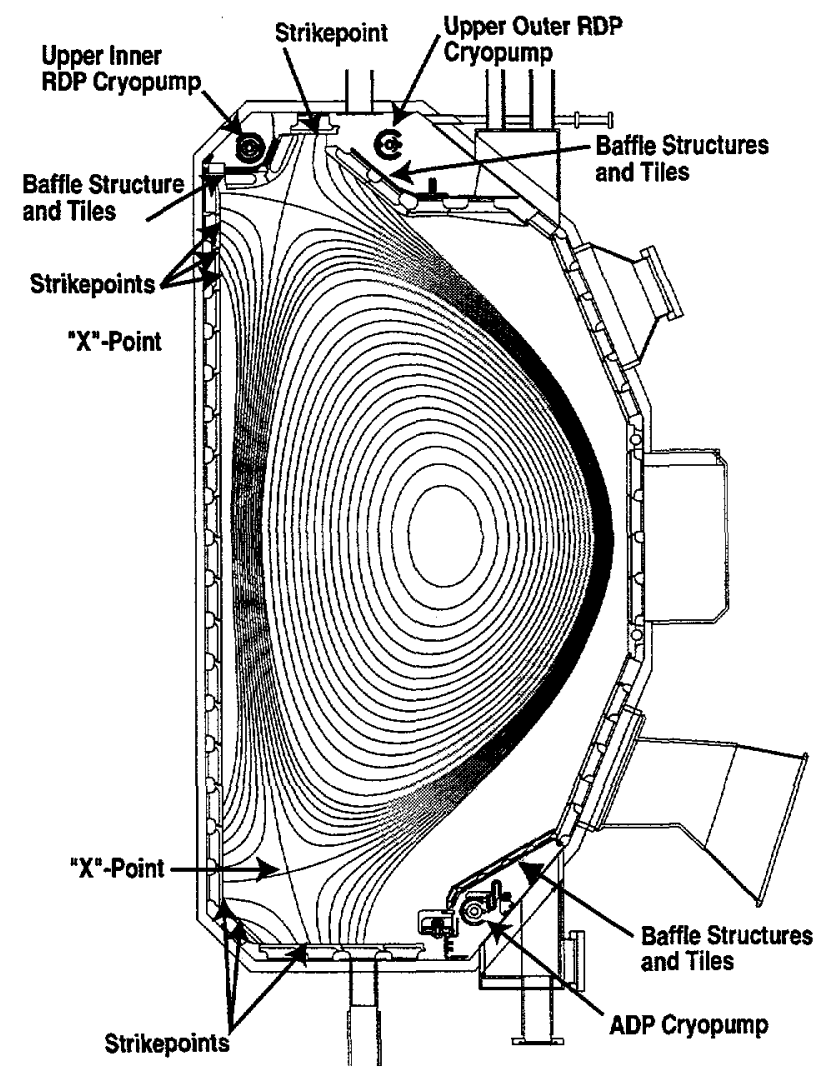

Fig. 1. General configuration of the radiative divertor and the advanced divertor (ADP) with double-null plasma field lines in DIII-D.

\footnotetext{
*Work supported by U.S. Department of Energy under Contract Nos. DE-AC03-99ER54463 and W-7405-ENG-48.
} 
$\mathrm{X}$-point to the target plate). The width may be increased to as much as $43 \mathrm{~cm}$ with new tiles and the lowering of the divertor structures. The hardware permits either single- or double-null experiments. The design enables continued research of wellconfined high beta divertor plasmas with noninductive current drive, which is one of DIII-D's main research goals.

The cryopump of each structure, in conjunction with the baffles, collects particles and prevent them from recirculating back into the plasma core. The particles are then exhausted from the cryopump surface as the pump warms between plasma shots. Having two pumps on the top of the vessel will allow pumping directly above and outboard of the private flux region. With this unique capability of pumping and injection of gases, various diagnostics are required to understand impurity transport and plasma flows. Diagnostics such as Langmuir probes, bolometers, ASDEX pressure gauges, various spectroscopic equipment and current monitors [2] are positioned in and around the divertors to monitor the scrapeoff layer, plasma and separatrix.

\section{CRYOCONDENSATION PUMP}

Each of the three divertor systems contains a cryopump that is a toroidally continuous coaxial tube. The space-saving continuous tubes minimize the potential of electrical breakdown in the low density environment. The inner $2.5 \mathrm{~cm}$ diameter Inconel tube of the coaxial arrangement is cooled with liquid helium to $4.3 \mathrm{~K}$. This tube is electrically isolated from the vessel, as well as from the surrounding $8 \mathrm{~cm}$ diameter liquid nitrogen shield. The liquid-cooled nitrogen shield is the primary structural support of the cryopump and is surrounded by a $9.5 \mathrm{~cm}$ diameter particle shield, which limits the particles impacting the nitrogen shield and prevents condensed vapors from desorption. The Inconel nitrogen shield also limits the heat flux onto the helium-cooled tube.

The cryopumps are attached to the vessel wall or ceiling with a series of brackets [3]. Each support bracket consists of two major components: (1) a rigid " $Z$ " or " $L$ " bracket which is bolted directly to the vessel wall, and (2) a flexible hoop or " $S$ " bracket which serves as the interface between the rigid bracket and the cryopump itself. The hoop or " $\mathrm{S}$ " bracket permits radial motion during cooldown of the pump and during thermal baking of the vacuum vessel. Also, the support limits the vertical displacement of the pump during plasma disruptions.

Each pump's nitrogen and helium supply/return lines enter the vessel via vertical floor or ceiling ports. The spacesaving concentric helium feed line supplies liquid through the inner tube while the helium returns via the outer annulus. The nitrogen supply and return are housed in separate tubes that are welded to a shield or shell surrounding the helium tubes. This serves to cool the shield and protect the helium tubes from heat flux. These lines, in excess of $2 \mathrm{~m}$ in length, are designed to flex horizontally between the fixed vessel vacuum flange and the weldment to each of the cryopumps. This is to accommodate the thermal expansion and contraction of the cryopumps.

\section{DIVERTOR STRUCTURES}

Each of the divertor structures consists of either two or three toroidal continuous water panels. Made of Inconel 625, the panels are of a welded sandwich construction. The structures, though subjected to large toroidal current during disruptions, can accommodate the induced loads during the collapse of the plasma. The water panels consist of either four $90^{\circ}$ sections or three $120^{\circ}$ sections that are pinned and welded together to form a continuous ring [4]. To further enclose the cryopumps of the upper outer and lower outer advanced divertors, Inconel 625 plates are used to bridge between the water panels and the vessel wall. The radiatively cooled plates are easily removed to service the diagnostics in and around the cryopump. In addition to the plates, strips of stainless steel are positioned between each of the plates and cooling panels. These strips serve to close off conductance paths from the pumping area to the plasma chamber, effectively preventing back streaming of particles into the plasma from the pumping plenum.

The water-cooled panels are supported from the vessel wall and ceiling by brackets similar in design to the rigid brackets used to support the cryopump. Providing an electrical current path, the brackets, made of Inconel 718 , react the disruption and halo current loads on the panels, and allow for thermal differential growth between the panels and the vessel.

The brackets for the cooling panels are, for the most part, protected from direct plasma exposure by the shadowing created by the panels themselves. To protect the areas of the brackets not shadowed by the panels, tiles made of 2-D carbon-carbon material have been employed to intercept field lines/heat fluxes that may impinge upon the bracket surfaces. The radiative cooled tiles are mounted directly to the panel brackets themselves or, in the case of the upper inner divertor structure, attached to special supports which are mounted to the vessel center post wall. The majority of these supports are made from Inconel 625 , but six of the supports have been fabricated from vanadium alloy (V-4Cr-4Ti) (Fig. 2). Vanadium was selected as the material for the support to demonstrate the in-service characteristics of the alloy, which is considered a candidate for future tokamaks because of its low induced radioactivity and rapid decay. The supports have been welded with two methods: (1) gas tungsten arc, and (2) electron beam. In addition to the welded vanadium supports, charpy impact and tensile specimens of the parent material, as well as the two weld materials, have been placed adjacent to the brackets. This will allow for the monitoring of the material and the welds for impurities and temperature effects each year without removing or destroying the supports.

\section{TILES}

Graphite tiles are used to protect all three of the Inconel divertor panels and vessel. The inertially cooled tiles are mechanically attached to the water panels and vessel wall via a stud-clamping arrangement. The ability to unclamp tiles 


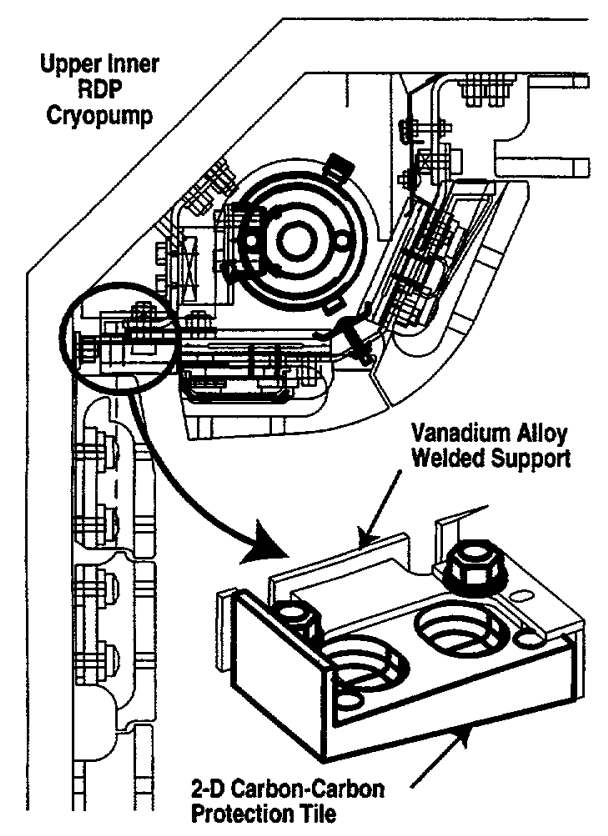

Fig. 2. Vanadium alloy support which protects the baffle bracket.

easily allows for quick changeout of tiles. With this capability, tiles of various heights, widths and lengths may be installed in a minimum amount of time and permit the adjusting of the baffle slot structure width and depth depending on physics research requirements. To improve thermal transfer of the heat deposition on the tile surface to the water-cooled vessel or panel, Graphoil囚, a graphite mat, is sandwiched between the vessel wall or panel and the foot of the tile. The thermal capabilities of the graphite tiles are $5 \mathrm{MW} / \mathrm{m}^{2}$ for $5 \mathrm{~s}$ or $3.8 \mathrm{MW} / \mathrm{m}^{2}$ for $10 \mathrm{~s}$, with a maximum surface temperature of $1500^{\circ} \mathrm{C}$ before ablation occurs. During plasma operation, the tiles absorb energy from the plasma and are allowed to cool to $30^{\circ} \mathrm{C}$ in $10 \mathrm{~min}$ between plasma pulses.

To minimize ablation of tile edges from peak heat impingement, great effort is being given to align the tile top surfaces so that they are continuous [5]. The gaps between tiles are also being reduced to less than $1.5 \mathrm{~mm}$ to minimize the exposure of the tile edges for the upper two divertor systems.

\section{DIAGNOSTICS}

Various diagnostics are used to monitor the plasma in the divertor areas to gain a better understanding of plasma flow, scrape-off layer (SOL) characteristics, impurity transport, baffle pressures, heat flux reduction and frictional forces. Well over 50 diagnostics are employed to measure the power balance, particle transport, erosion and sputtering of graphite, gas density and SOL parameters of divertor plasmas. To measure surface temperatures of components in the immediate divertor area, six infrared cameras are used. The 8-12 $\mu \mathrm{m}$ light emission with a $125 \mu$ s resolution of the cameras is used to infer the local heat flux. To measure the plasma radiative losses, two sets of bolometer arrays, 24 viewing chords each, are used. The bolometer arrays not only give complete poloidal coverage of the divertor plasma, but also of the core plasma. Accompanying these bolometers are foil bolometers. The foil or $2 \pi$ bolometers are $1.25 \mathrm{~mm}$ thick graphite foils that are attached to the plasma-facing tile surface. The timedependent behavior of the foil surface temperature provides a quantity of radiated power impinging on the foil surface [6]. Measuring electron temperature and plasma density are the Langmuir probes. The probes directly measure the heat and particle flux of the plasma as with the bolometers.

Also providing crucial plasma temperature as well as density measurements, is the Thomson scattering optics. The optics view a series of laser beams that pass vertically through the plasma and measures the density in local area. Interferometers and reflectometers provide line integrated density, density profiles and peaks.

To determine impurity concentrations in the divertor plasma, the SPRED XUV measure the impurity brightness or light. This spectrometer measures the column integrated brightness of impurities along the view chords adjacent to the Thomson vertical laser beams. The Thomson beam diagnostic determines the electron density and temperature. With the brightness of the impurities, the electron density and the electron temperature, the impurity concentration can be calculated since the electron impact excitation (the source of light or brightness) cross sections are well known.

\section{OpERATIONAL RESUlts}

Many experiments have been conducted using the two existing DIII-D divertors [the upper outer divertor (Phase 1A) and the lower outer advance divertor (ADP)]. The experiments have investigated the performance of baffled and open divertors (cryopump off) with single-null plasmas, particle control in baffled and open divertors and particle control in double-null plasmas [7]. Since the divertor experiments are numerous, with interesting and informative results, only density control experiments will be discussed to provide a full explanation of the experiments and results.

Density control in the core plasma and separatrix is of special interest since it directly influences the efficiency of $\mathbf{r f}$ current drive or coupling to advance tokamak plasmas. Increasing this efficiency will ultimately increase the capability of delivering energy into the plasma. The density control and exhaust capabilities of the DIII-D divertors are directly related to the " $X$ "-point and the strike-point positions. Moving the strike points closer to the baffle structure and cryopump increases the exhaust of particles and decreases the separatrix and core density while maintaining the plasma current.

To further enhance the exhausting of particles and to reduce heat flux, gas is puffed into the separatrix and SOL. Figure 3 shows the effects of the movement of the $X$-point and strike point in relation to the density or $n_{e} / I_{p}$ (plasma electron density/plasma current) with the cryopump operating. 

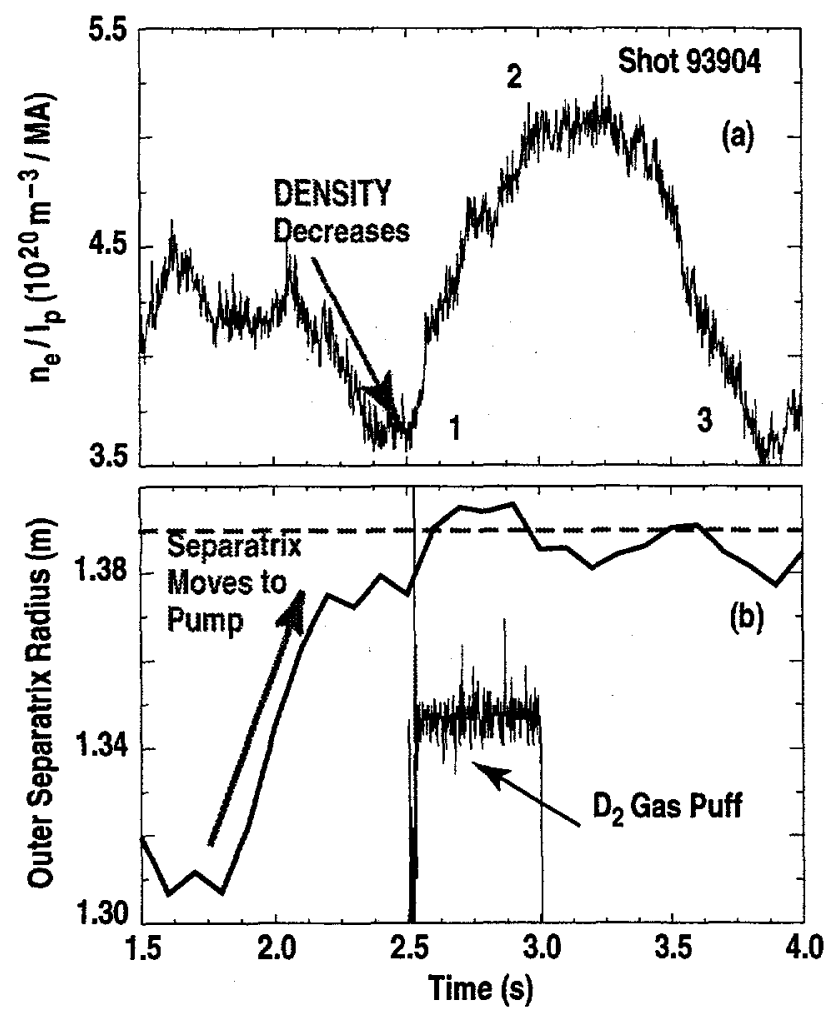

Fig. 3. The density normalized to the plasma current versus time for an ELMing H-mode discharge, note three times: (1) the strike point is swept towards the pump and the density decreases, (2) a deuterium gas puff is introduced and the density rises, and (3) after the gas puff, the density again decreases.

As the $\mathrm{X}$-point moves closer to the pump, the density decreases. With $D_{2}$ being puffed into the separatrix, and the $\mathrm{X}$-point radius remaining constant, the density obviously increases and then falls off once the puffing ends. The core plasma electron temperature increases after the gas puff, as seen in Fig. 4. The numbers 1,2 and 3 on Fig. 4 refer to the temperature or density prior to, during and after the gas puff while $\rho$ refers to the radial location of the plasma. This phenomenon of increased plasma temperature as the density decreases requires more study to explain why this occurs. As future experiments are conducted, the underlying physics controlling this event will be determined and understood.

\section{SUMMARY}

With the installation of the upper inner divertor, the Radiative Divertor Program is further enhanced in its capabilities and flexibilities in the research of particle transport, heat flux reduction and impurity control. The versatile divertor structures and cryopumps allow for active pumping and assist in confining the neutral gas. With a variety of diagnostics and the capabilities of DIII-D operation, many divertor experiments may be performed to further understand the physics of plasma flows, confinement and exhausts.

\section{REFERENCES}

[1] J.P. Smith, et al., "A Cryocondensation Pump for the

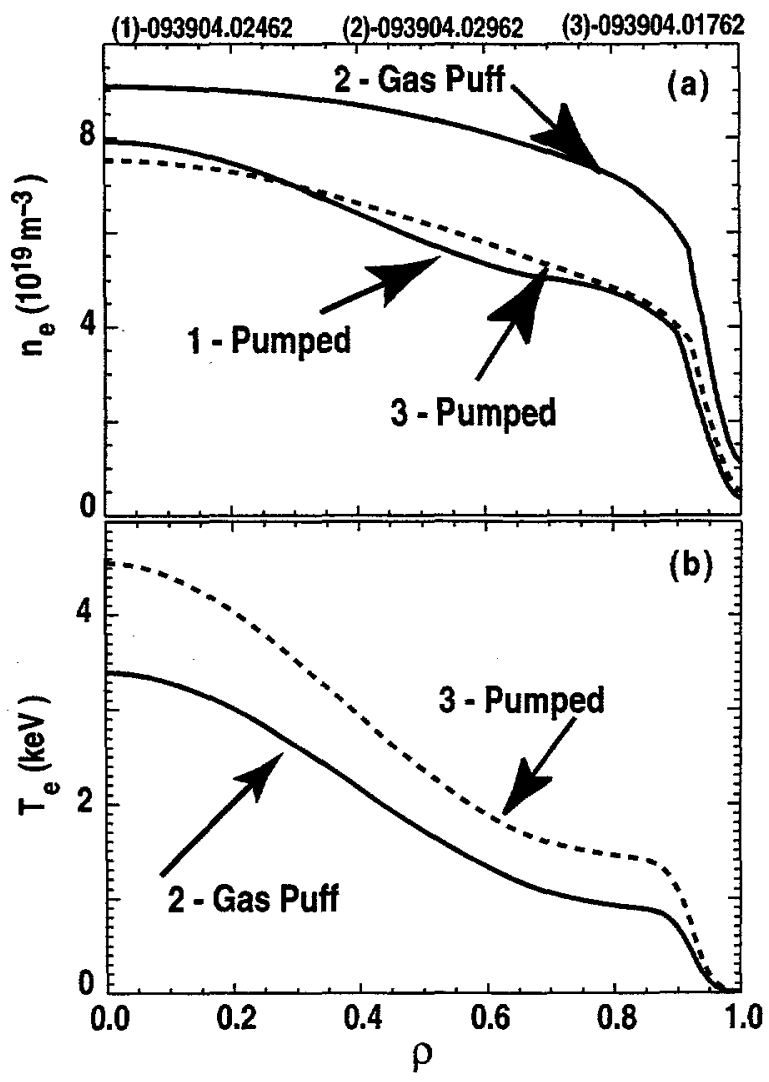

Fig. 4. The (a) electron density $n_{e}$ and (b) electron temperature $T_{e}$ profiles from Thomson Scattering for the three times in Fig. 4. The main features of the profile are similar in each case.

DIII-D Advanced Divertor Program," Proc. of the 10th Top. Mtg on the Technology of Fusion Energy, Boston, Massachusetts, 1992, Vol. 2, page 1658 (1993).

[2] D.G. Nilson, et al., "Diagnostics for the DIII-D Radiative Divertor," Proc. of the 16th Symp. on Fusion Engineering, Champaign, Illinois, 1995, Vol. 1, 808 (1996).

[3] A.S. Bozek, et al., "Engineering Design of Cryocondensation Pumps for the DIII-D Radiative Divertor Program," Proc. of the 16th Symp. on Fusion Engineering, Champaign, Illinois, 1995, Vol. 1, 898 (1996).

[4] M.A. Hollerbach, et al., "Design and Analysis of the DIII-D Radiative Divertor Water-Cooled Structures," Proc. of the 16th Symp. on Fusion Engineering, Champaign, Illinois, 1995, Vol. 1, 817 (1996).

[5] M.E. Friend, et al., "Reduction of Tile Edge Heating in the DIII-D Tokamak," these Proceedings.

[6] D.N. Hill, et al., Rev. Sci. Instrum, 59, 1878, 1988.

[7] S.L. Allen, et al., "Studies of High- $\delta$ (Baffled) and Low- $\delta$ (Open) Pumped Divertor Operation on DIII-D," J. Nucl. Mater. 266-269, 168, 1999.

\section{GENERAL ATOMICS REPORT GA-A23284}

